\title{
Feng Shui in Anthropological Research - Between Perception and Apperception
}

\author{
Špela KRYŽANOWSKI \\ * Faculty of Design, Associated Member of the University of Primorska, Slovenia \\ E-mail: spela.kry@gmail.com
}

DOI: 10.29322/IJSRP.10.11.2020.p10775

http://dx.doi.org/10.29322/IJSRP.10.11.2020.p10775

\begin{abstract}
Feng shui is a traditional Chinese art of designing the environment that incorporates both rational and irrational (mystical) paradigms. In a unified concept, it connects the physical environment, psychology, social relations and the world of the spiritual. In the beginning, the paper analyses the historical and contemporary fengshui anthropological research. It concludes, that feng shui is viewed by most researchers through the perceptual (rational - logical) perspective of an independent external observer, with descriptions ranging from highly critical (a hindering of development or pseudo-natural science) to more lenient (popular religion, cultural geography or cosmology in practice). Only a few people seek to experience feng shui space features personally, through apperception or artistic expression. These apperceptual experiences are supplemented by a twodecade-long case study with the author's participation. It is shown that the practical apperceptions of the energy structure of the physical space can be quite different from fengshui's theoretical starting points. Based on the experience of self-perception, three concepts of generating an energy field in physical space are set up, complementing the feng shui perspective. Feng shui is more than just an example of cultural globalization or a successful historical metaphor because it has the potential to change the existing spatial paradigms.
\end{abstract}

Keywords- feng shui, anthropology, apperception, selfparticipation

\section{INTRODUCTION AND METHODOLOGY}

$F_{\mathrm{d}}$ Feng shui is the traditional Chinese art of environmental design, which is supposed to support the user as much as possible. It is grounded in traditional Chinese philosophy and closely embedded in the Chinese cultural-historical framework. The purpose of this article is to analyse anthropological scientific contributions on feng shui from the point of view of rational analysis (perception) or through the feeling of physical space (apperception). There are two aspects in feng shui that make this traditional art very different from contemporary design practices. These are the concept of the life force $q i$ and the belief that the well-being of the individual is also significantly influenced by the spirits of the deceased family members. In feng shui, both nature and landscape formations and, of course, cities and objects are treated as living beings. The orientation of the building according to the compass direction, the time of construction of the building and the user's birthday should also create a specific pattern of qi. $Q i$, however, is not the only intangible force in feng shui to co-engineer the quality of life. The spirits of the deceased family, who are supposed to be properly cared for through the cult of ancestral worship, are also playing an important role. Paton sums up the words of the 65th-generation Taiwanese feng shui practitioner He Jinzong when he claims that "feng shui in $50 \%$ depends on the position of the grave of the ancestors, $35 \%$ on the position of the house or workplace concerning the external manifestation of the life force qi and only $15 \%$ on the internal arrangement of the house or workplace concerning the internal flow of the life force $q i^{\prime \prime}$ (Paton in Mak et al., 2009, 46). From this short outline, it can be established that feng shui operates with concepts that are foreign to modern sciences and which are not easy or even possible to analyse with the current scientific apparatus. It extends both to the realm of rational (when describing the natural phenomena and recommending how we should build dwellings to make the most of the environment) and to the irrational (when defining the energy structure of the landscape or the connection between the world of the living and the dead). It is this connecting of different aspects (physical environment, psychology, social relations and the world of spiritual) into a uniform concept, that is one of fengshui's essential qualities. To better understand (and experience) it in all its integrity, we should therefore use both the tools of perception and apperception in the research. To determine whether this is true in the way feng shui is researched, anthropological contributions on feng shui are systematically analyzed in the central part of the paper. We wanted to examine whether they are entirely based on rational analysis and logical reasoning, or perhaps also using tools of direct experience and apperception. As an example of the latter, the personal experience of the author is presented.

In the preview, qualitative analysis with document analysis (Bowen, 2009) and desk survey (Juneja, 2020) was used. A systematic and comprehensive review of scientific papers published in professional books, journals, reports and newspapers (Creswell, 2009) was carried out, using the terms 'feng shui' and 'Chinese Geomancy'. The search included the period up to 2019 in the Springer, JSTOR, ProQuest and Google Scholar web bases. All contributions relating to feng shui were included in the first review. From the set of approx. 3,000 hits approx. 300 contributions were selected, based on the criteria of authenticity, credibility and representativeness. They were examined and classified into 7 thematic groups: anthropology, economics, health, modern Chinese scientific research of feng shui, urbanism and architecture, sustainability and evaluation studies 
(Kryžanowski, 2019). For this research, the first group has shown to be essential.

\section{FENG SHUI AND NOTIONS OF PERCEPTION, APPERCEPTION AND ABDUCTION}

Feng shui touches on many diverse fields, from art, through social sciences and humanism to science, each with its research instruments and protocols. As we will see below, the researchers' contributions are based primarily on perception and logical reasoning, and few have a direct experience of feng shui physical space. Perception is defined as an awareness of the elements of environment through physical sensation (Merriam, 2018). As a rule, it is an objective (usually instrumentally measurable) perception, which is the result of the functioning of our five senses. In contrast to perception, apperception is in its essence distinctly personal and subjective. Apperception by definition means introspective self-consciousness (Merriam, 2018). It is a personal inner feeling that goes beyond mere external objective sensory perceptions. In feng shui, we can detect two opposite research positions: rational and mystical. The rational position is well known and represents the basis of contemporary scientific thought. The physical space and its users are analysed through the tools of physics, geology, history, architecture, psychology, humanities, etc. The position of the researcher as a neutral observer is required in this role. The posture of the mystical (or apperception) researcher is distinctly personal and subjective. A mystical researcher obtains information through deep internal insights, dreams, hunches, clues or various mystical techniques. The information obtained may seem pointless to the external observer, even absurd and inexplicable with a logically rational scientific apparatus. Bateson $(2000,78,86)$ points out that new scientific knowledge can only be found with a combination of a loose and strict way of thinking, regardless of the area of science. For him, this combination of thinking is the most valuable tool of science. It often happens that those who initially create a new structure from a loose way of thinking are different persons than those who afterwards purify this structure. Sometimes centuries pass between the first and second processes. In this context, feng shui is certainly a combination of a loose and strict way of thinking, although, from the position of modern science, we view it primarily as a loose (metaphysical) and less as a strict (rational) mental product. Feng shui can also be seen as the result of the abductive way of thinking. It is a strategy of reasoning which, based on the data provided, offers the most likely explanation of the phenomenon (hypothesis). In the absence of extensive statistics (with which modern science usually operates), the protagonists of feng shui, based on careful observations and in combination with mystical insights, have developed hypotheses (the most likely explanations) for observed phenomena. Pierce (in Paavola, 2004) does not talk about mystical insights when he discusses abduction. He talks about the inner instinct that directs us to choose the most likely hypotheses among the many possible.

\section{THE HISTORICAL ANTHROPOLOGICAL APPROACH TO FENG SHUI RESEARCH}

Anthropological research into feng shui throughout history is mostly perceptual, i.e. as neutral and objective as possible. As a rule, the personal experience of feng shui is not the subject of researchers. The beginning of western European study of Chinese geomantic can be traced back to the late 19th century when Eitel's book Feng shui or the Rudiments of the Natural Science in China (Eitel, 1873) was published. Eitel, a Protestant missionary in China, first and foremost saw feng shui as an excuse for local authorities and residents, against building new roads and railways, erecting telegraph poles or building new settlements. For Eitel, feng shui is nothing but nature science, a collection of recommendations that are available to us by our instincts and intellects, which the Chinese have wrapped into mystery or turned into black magic. Eitel (2015) notes that the Chinese thinking is similar to ancient Greeks and many Renaissance thinkers, namely that nature is a living organism, where its every part, be it dead or alive, is imbued with spirit or life.

In 1892, the Dutch sinologist De Groot began publishing his monumental work The Religious System of China (DeGroot, 1897), which also features an in-depth analysis of feng shui, based on fieldwork and studies of classical writings. It exposes two origins of feng shui, namely the cult of ancestral worship and the cult of worship of nature as a living being. For De Groot, feng shui is a collection of childish absurdities and sophisticated mysticism, held together by an elaborate system of understanding, which is merely a funny caricature of science (De Groot in Bruun, 2008, 43). De Groot's contemporary Boerschmann spends three years in China and he is more lenient on feng shui in his book Picturesque China: Architecture and Landscape (Boerschmann in Parkes, 2003, 190).

In the postwar period, the interest in anthropological research into feng shui continues. Feng shui is mentioned in the extensive work of Needham Mathematics and the Sciences of the Heavens and Earth (1962). For Needham, feng shui is a pseudoscience that carries a rational grain of understanding the natural laws (Needham in Freedman, 1968). Although Needham doesn't pay much attention to feng shui, it paves the way for more lenient assessments of feng shui with a focus on ecology. The British structural-functionalist Freedman (1968) defines feng shui as a mystical ecology or ritualization of elements of time and space. Feng shui is perceived as a determinant, as the complexity of the functioning of the universe is reduced to the problem of appropriate spatial (and temporal) adaptation of man. Unlike Needham, Freedman characterizes it as a form of Chinese religion which is not related to a single faith, church or priest, but is changing them according to current personal needs (Yang in Bruun, 2008, 87). He also defines feng shui as social relationships stabiliser and, at the same time, a catalyst for community competition. For example, by clearly defining the rules of where a wall can be or how high a house can be, envy and jealousy are also indirectly regulated. And when an accident occurs, it's the fault of bad feng shui or supernatural forces. In this context, feng shui practitioner is primarily a mediator between the physical and supernatural world (Potter in Bruun, 2008).

March in An appreciation of Chinese Geomancy (1968) offers a fresh and different view of feng shui, which, unlike its predecessors, also derives from apperception. For March, the most important thing is the feeling of space, the interplay of psyche and landscape, and the direct personal experience is of exceptional importance. Feng shui is therefore supposed to enable the individual to feel directly the breath of the landscape, its viability 
and diversity, which stems, among other things, from the interweaving of female yin and male yang forms and the flow of landscape's qi life currents. A real fengshui location can be experienced as very special, which is difficult to describe in words. The sense of space is crucial for March, although the paper also touches on other aspects of feng shui, which have already been pointed out by predecessors (for example, a motivational aspect that encourages the individual to pull out and succeed despite the uninspiring situation). It also highlights the synchronistic nature of feng shui (associated with Jung's teachings) where amazing but important coincidences occur in physical space, which do not arise from causation (cause-effect relationship). For March, feng shui is an example of the system through which the will of heaven is exercised.

A few years later, Feuchtwang publishes a much-quoted work An Anthropological Analysis of Chinese Geomancy (Feuchtwang, 1974), in which he conducts a comprehensive analysis of feng shui based on twenty-four traditional texts. In the analytical work, he identifies four roles in which feng shui occurs: classification in feng shui is supposed to reflect the social divisions of society, imagination is expressed in feng shui through symbolism and psychological projections, feng shui can be understood as a divination technique, and the fourth is the role of feng shui as a specific way of detecting reality. For Feuchtwang, feng shui is a way of self-identifying (identification) a person or group (family) through the choice of location, where the location also becomes a centre of personal interests. It highlights the activist role of feng shui, whose basic tool is a metaphor used to explain the fate of an individual (Feuchtwang in Bruun, 2008, 90).

From Chinese anthropologists of this period Yang and his work Religion and Chinese Society (Yang in Bruun, 2008, 90) should be mentioned, which emphasizes the political aspect of the popular Chinese religion and the importance of the cult of ancestral worship. Yang explains that religiously motivated uprisings have always occurred in Chinese society during periods of severe social conflict (e.g. political unrest and oppression), economic decline (e.g. in times of severe hunger) and social disintegration. The pressures have repeatedly resurrected faith in supernatural forces, powers and miracles. In the 1970s and 1980s, there are only a few articles published on anthropological research of feng shui, most likely due to the closure of the People's Republic of China (Watson, 1976). Most of the research is therefore carried outside China's borders: Hong Kong, Taiwan and other Chinese communities of Southeast Asia.

\section{THE MODERN ANTHROPOLOGICAL APPROACH TO FENG SHUI RESEARCH}

Even in the last 20 years, interest in the scientific study of feng shui has not faded. The focus, however, remains on the rational analysis of feng shui. For Hwangbo (1999, 191), feng shui is "an ancient architectural theory, /.../ a mixture of art and science." It highlights the political, religious and philosophical subordination of architecture in Chinese culture, as it has never developed as an independent profession suitable for a Confucian scholar. Therefore, feng shui practitioners took over the role planners and construction coordinators in rural areas where educated people were scarce. Hwangbo's focus is on the useful aspect of feng shui.
The essence of feng shui techniques lies in creating an order in a built environment that mimics the perceived order in life. It points out that many pragmatic elements in feng shui can also be found in modern architecture (e.g. quality sun exposure, protection from wind and other negative impacts). Therefore, the study of feng shui should also be seen not only as a rediscovery of tradition but primarily as a way of creating new paradigms (Hwangbo, 2002).

Paton (2007) focuses on the original concepts of feng shui, as can be drawn from original texts from the period of early, medium and late imperialist China. $\mathrm{He}$ is the author of the book Five Classics of Feng shui (Paton,2013). The first part of the book offers an in-depth overview of classical and contemporary literature of feng shui, the second part is a translation of five classic fengshui texts. It focuses on the scientific nature and historical development of the fengshui school of form. Paton is critical of the modern use of feng shui and its association with new-age content, such as energy cleaning, radiesthesia, holistic health techniques, mysticism, etc., although it also notes that this kind of layering is not only typical of modern times but has always been one of the key features of feng shui (Paton, 2013). He is also critical of the excessive generalisation through which feng shui is easily transmitted to other cultures, without understanding the essence and the basics.

The German sinologist Kubny $(2008,270)$ points out that the use of the term Chinese metaphysics for traditional Chinese knowledge is inappropriate since the term suggests that the centre of understanding lies behind the explicable world. In the case of feng shui, it is primarily about describing the influences of the power of nature (described by the term sky and earth - tiandi) on a man, who himself is a reflection of this same sky and earth (xiao tiandi). It is, therefore, an attempt to describe the structure of the physical world, but differently from that we are used to in modern science.

One of the most interesting contemporary anthropologists studying feng shui is a Danish researcher Ole Bruun. In Feng Shui and China, Geomantic Divination Between State Orthodoxy and Popular Religion Bruun (2003) explores the social aspect of feng shui through a combined historicalanthropological aspect. It focuses on the period between 1850 and 1990 and summarises the results of several of its field research in the Sichuan and Jiangsu areas carried out in the last ten years before the end of the millennium. He emphasises the importance of 'in situ' study of feng shui, always comprehensively taking into account the original cultural-historical environment (Bruun, 2003, 2). Feng shui is a form of Chinese cosmology in practice, where the geomancer strives to discover the ideal cosmological layout ( the one that reigns the sky) in a physical environment. For Bruun, traditional feng shui, where there would be only one theory and practice, does not exist at all, except perhaps in academic research (Bruun, 2003, 9). The nature of feng shui is distinctly composite, but there is also a difference between theory and the practical execution of both China's popular religion and feng shui. For Bruun, "feng shui is a living tradition that has a built-in ability to survive diverse social circumstances, as evidenced by its numerous historical and local modifications (Bruun, 2003, 255)". Like others before him, he highlights the sociopolitical role of feng shui, which, in the last 50 years (and previously in history) acted as a counterbalance of the local population against pressure from China's ruling elite. Feng shui can be seen as a reflection of the 
cosmologically justified resistance of the local population, where the divination of graves is its most religious element (Bruun, 2003, 260). He highlights the dual attitude that the ruling elite had towards the worship of ancestors where, on the one hand, it proclaimed such practices as superstitious and reactionary, and on the other hand, by destroying traditional graves, indirectly recognized the cult of ancestral worship as important. At the same time, the elite always used (at least to some extent) the services of feng shui practitioners at the burials of its family members. Images of irrational from local culture and popular religion always reflect all the important social and political themes of the time (Bruun, 2003, 35). Similarly, for the modern feng shui development in the Western world, it can be argued that it acts as a counterweight to the excessive political, economic and global pressure that seeks to monopolise ways of thinking through the aspect of rationality (Bruun, 2003, 257). In An Introduction to Feng shui Bruun (2008) upgrades his insights with, among other things, a detailed analysis of the relationship between feng shui and ecology and past and modern feng shui uses. And it is this ability to adapt that has made feng shui so influential throughout Chinese history since every element of everyday life can be linked in feng shui to individual elements of Chinese tradition (Bruun, 2008, 3).

\section{OTHER ASPECTS OF ANTHROPOLOGICAL RESEARCH INTO FENG SHUI}

Other contemporary anthropological contributions focus on diverse aspects of feng shui, but their analysing concept remains strictly rational. Many contributions try to present feng shui in its historical, philosophical and practical context (e.g. Hwangbo, 2002; Parkes, 2003; Yuan, 2008 or Li, 2014), others focus on specific aspects of feng shui. Emmons (1992) explores how this ancient form of magic has managed to remain in Hong Kong's rational and business-oriented culture for such a long time, Teiser (1995) analyses the phenomenon from the point of view of popular religion and Montenegro (2003) analyses the comparison between feng shui philosophical platform and Christian world view. Dawson (2006) examines the influences of Eastern thought on the Western way of thinking and concludes that Eastern concepts (e.g. the concept of spiritual growth or depersonalised view of the cosmos), when transferred, adapt to Western thinking modes without actually changing the existing Western paradigm. Other authors also study feng shui in conjunction with other cultures outside its original context (e.g. Braswell-Means, 1990 or Goodall, 2001). Leunga (2010) is interested in the analysis of feng shui in terms of individual belief system, Wan et al. (2012) are exploring how different ways of understanding feng shui affect the likelihood that people will use feng shui.

The cult of ancestral worship represents a special chapter in the anthropological study of feng shui. In addition to historical analyses (e.g. Abraham et al., 2003), researchers are also interested in the manifestation of the phenomenon in modern society. Teather (2001) examines the Hong Kong tradition of cemetery festivals and notes that even today, these festivals still serve their primary purpose, thus consolidating family ties in Hong Kong's dominant immigrant community. Chen (2016) analyzes the traditional burial ritual in a Chinese village, while Teather (1999) and Yang (2003) discuss a modern form of burial using cremation urns which puts entirely new challenges in front of architects in terms of feng shui. A special research topic is Chinese cemeteries, which were created in other cultural environments (e.g. Peters, 1998 or Lai, 1974 and 1987). For traditionally oriented Chinese, at home or abroad, funeral rituals remain an important part of collective identity.

\section{FROM REJECTING CRITICISM TO MORE LENIENT ASSESSMENTS}

All the contributions presented above are made from the standpoint of an independent external observer, i.e. objectively and rationally. Nevertheless, the changing attitude towards feng shui through history is primarily due to changes in Western society and not due to changes in feng shui practice. In the 19th century, initial curiosity was followed by a very dismissive reaction, in which feng shui was treated primarily from a perspective of superstition, irrationality and reactionism that inhibits development. We can find labels of feng shui as "funny caricatures of science" or "the mess of absurdity (De Groot, 1897, 938)" or "perverse use of physical and meteorological knowledge (Sarton in March 1968)". There is an element of racism in which the Chinese way of thinking is treated as inferior, and the Chinese as stubborn and resisting change. These critics come from an imperialist society that focuses on economic exploitation and is imbued with enlightenment philosophy and the principles of Western science. In the first half of the 20th century, the criticism becomes more compassionate and less dismissive, with a sincere desire for an in-depth understanding of philosophical basics. Poter (in Mills, 1999, 73) defines feng shui as "a historical remanence that points to human initial stages of truth-seeking." For Needham (in Mills, 1999, 73) feng shui is a pseudo-science. For modernists, feng shui is still irrational, unscientific and reactionary, but no longer threatening. It is perceived as an interesting historical or cultural phenomenon that cannot be easily classified into familiar categories. It is treated from a perspective of mythology, folklore, popular religion or cultural geography. Definitions of feng shui become more neutral, such as "popular religion (Freedman, 1968, 13)", "a belief system that shows where and how to erect a grave or house so that future prosperity is guaranteed (Eitel in Froehling, 2015, 7)". March (in Mills, 1999) is one of the authors, that talk about the deep sensing of the landscape through "connecting the psyche and the landscape". He is the only of the presented authors who gives a personal experience of what feng shui is about.

\begin{abstract}
"In the right location /.../ the light is magical. How magical? It can be understood intuitively, but its meaning is difficult to convey in words. The hills are beautiful, the waters are good, the sun is pleasant, the breeze is mild and the sky is illuminated by a special light: another world. There's peace in the confusion, there's a festive feeling in peace. When you get into the presence of space, the eyes open, if a man sits or lies down, the heart fills with joy. This is where the breath gathers and the essence focuses. The light shines from the middle, and the magic extends to all sides. /.../ Try to understand this! It's hard to put into words." (March,1968, 259)
\end{abstract}

The lenient definitions of feng shui continue over the past two decades. Hwangbo $(1999,191)$ defines it as ancient architectural 
theory and Bruun $(2003,2)$ as a realisation of Chinese cosmology in practice.

\section{APPERCEPTION AND ARTISTIC EXPLORATION OF FENG SHUI}

Only March shifts from the role of a researcher using perception to the role of using apperception, the one who is personally experiencing feng shui in physical space. This form of personal participation and use of common sense is often used as a scientifically appropriate method in the research process, especially in social psychology and sociology. Hamel (1997) presents Tourain's method of social intervention, where actors of a social movement (e.g. students, women, environmentalists and workers) are active participants in the design of the theoretical framework of their social movement using their experience, selfanalysis and the help of professional sociologists. Common sense psychology is also known by the terms naïve psychology, ethnopsychology or indigenous psychology (Kelley, 1992). It is characterized by the use of everyday language to describe various psychological phenomena (see e.g. Heider or Smedslund (both in Kelly, 1992). Feng shui is largely the product of a common-sense way of thinking.

Other identified contributions describing the experience of feng shui through apperception belong exclusively to the field of art. Dong (2017) in Integrating Feng Shui Concepts into Painting Creation shows how he uses feng shui principles in painting (e.g. $q i$ concept, the contrast of yin and yang, five elemental phases). Before he starts to paint, he focuses and collects $q i$ in his body and then expresses it through brush strokes and the choice of colours. He describes the experience as very emotional, explosive, spiritual and out-of-body. In his paintings, the worlds of East and West are brought together, and Dong sees his concept of painting as a structure that can be used in both painting, sculpture or any other art. His artwork combines the philosophical essence of feng shui with the expressive means of modern Western culture.

China Blue is a conceptual artist who explores the links between art and technology and between architecture and culture. $\mathrm{He}$ is looking for new typologies of expression, and one such artistic matrix is feng shui (Blue, 2003). The work uses a commercial feng shui concept, in which certain areas in the room relate to areas of the user's life, which he upgrades using modern technology. The qi concept is used in a way that the energy of a person (e.g. movement in a room) is 'translated' through sensors into music sound or light. In this way, it creates a sequence of events triggered by the presence or energy of the person entering the room. Laura's Jobbering Jobberwocky light is an artistic object, whose motion sensors trigger the play of the Jobberwocky song. With China Blue (unlike Dong), it is not about a personal experience of feng shui, but about using feng shui as a structural matrix for artwork. Feng shui also appears as a cultural backdrop in novels (see e.g. Hsu, 2006 or Vittachi, 2009).

\section{CASE STUDY THROUGH SELF- PARTICIPATIVE APPERCEPTION}

The examples of Dong and March show that the concept of life force $q i$ can be regarded not only as a metaphysical concept but as a physical phenomenon that can be experienced or observed through its effects. This view is also supported by the results of scientific research confirming the existence of external qi (e.g. Lu, 1997) and showing that $q i$ can influence substances such as water, DNA or atomic nuclei without physical contact (e.g. Yan, 2018.). $Q i$ has properties of matter and energy, and due to the current limitedness of existing experimental methods, many of its properties can't be examined in depth experimentally.

I have scientifically researched feng shui for the past 20 years (Kryžanowski, 2012a and 2019) and along with that also through self- participative apperception. The basic training to detect external and internal qi (also known in the Indian tradition as prana) was achieved through the practical study of radiesthesia, bio-energy healing, reiki, regular daily practice of meditation and encounters with highly spiritually developed persons. I also designed feng shui projects (see e.g. concept of a vital house in Kryžanowski, 2012a) and performed feng shui studies for clients.

Based on my own experience I estimate that the ability to detect or feel $q i$ is primarily the result of choosing a proper technique and being disciplined in doing the exercises. In the same non-mystic way as acquiring any other competence. The flow of life force $q i$, which I perceive in my body, feels like a stream of energy with properties of water, wind and electricity that can also cause an emotional sensation. The quality and intensity of the current can vary greatly, and I can generate the current myself through the use of willpower and focus (in a similar way as Dong describes it) or I can only observe it. In this case, I do not generate it myself, my role is the role of the observer. Some perceptions are barely noticeable others are strong and intense. Over the years, I have developed an evaluation system for the qi currents that I do not generate myself.

Based on the intensive multidisciplinary research of feng shui and my personal apperceptive experience of the energy structure of the physical space, I conclude that my experience does not confirm what feng shui theory teaches about qi patterns in physical space. Especially those of the feng shui school of compass, where certain segments of the room are expected to have a favourable or non-favourable impact due to their specific compass orientation or time component. Similarly, I never detected the flow of $q i$ in open landscape or inside an apartment in the way that the school of form teaches. Of course, this does not necessarily mean that such currents do not exist. I may be simply insensitive to the $q i$ flow as explained by feng shui. For me, the life potential of physical space is more like a field with different qualities, rather than an empty physical space in which currents flow. At the same time, I have some intense experience, through which I know that the physical space can be (very much) alive, but I can't connect them to the fengshui teachings.

One of these experiences comes from Mithra's Shrine in Ptuj (Slovenia). When I entered the hall, I detected a brutally intense stream of energy in the middle of the room, which in its character was very primordial and raw and, in the shape of a pillar with a diameter of about two meters lifting from the ground vertically upwards. The current was so strong that I would not be able to sit on the floor in its immediate vicinity, even if it wanted to. I quickly left the hall. The current was detected by a couple of colleagues through their bodily sensations or by radiesthesia instruments. It felt like my body was on fire and it could selfignite. My impression was that this was an energy source that was 
reviving this part of the landscape and that the shrine was erected mainly to prevent people from wandering too close. Years later, I returned to that same shrine, but the current was gone or was not active. It is worth noting that the feng shui school of form talks about xue points, in which the earth's energy qi, comes out on the surface of the landscape. Other intense perceptions of energy flows or fields that I experienced are related to physical spaces that have a spiritual (or religious) nature. Although I was raised in an atheist belief, I occasionally visited the Catholic church rites for family reasons. During one of these rituals, an extremely strong energy current poured from the ceiling of the church down onto the public. I estimate that the priest who led the ceremony did not sense it. I got the impression that religious rituals (as a rule) were designed in a way that invokes spiritual energy flow, which in religious terminology is called a blessing. But it doesn't always happen. In similar Catholic and Hindu rituals which I attended this was not the case. On the other hand, I have the experience of strong energy fields around the altars in several Indian temples, regardless of the presence of a ceremony. I also have years of repetitive consistent experience of a clear perception of a strong energy-spiritual field created by highly spiritually developed creatures (such as Satya Sai Baba or Stephen Turoff). All those experiences made me wonder, whether the vitality of physical space is the result of special physical factors (like e.g. feng shui) or if it is the result of the people and processes that occur in the physical space.

Based on the apperception experience so far, I estimate that energy fields in physical space are generated in three ways. Firstly, the fields may be the result of a specific location of the physical space (e.g. the aforementioned energy spring at the Mithra's shrine in Ptuj) or the special arrangement of physical space (e.g. vitality, which according to Alexander (2002a, 2002b, 2004 and 2005) comes from the geometric structure). Both aspects are also part of fengshui teachings. Fields can also be generated artificially in physical space, due to the so-called bio-generators. I would say that in this way the energy fields in the tunnels of the Bosnian pyramids (see, for example, Osmanagich, 2014) are created. Secondly, fields are generated in a particular space permanently due to repetitive processes or rituals (for example, energy fields around altars in temples and ashrams in India) or a unique special event (for example, energy fields generated in a place where a highly spiritually developed person has entered a mahasamadhi (conscious self-execution or planned exit of the soul from the body). Energy fields can also be generated in space temporarily (for example, an energy field created during Turoff's light circle meditation). Thirdly, energy fields are generated around a highly spiritually developed person and are not bound to a specific location. It is worth noting that, in my experience, an energy field generated by a highly spiritually developed person has a completely different quality than the energy field generated technically (e.g. in the tunnels of the Bosnian pyramids) or as a result of a specific location (e.g. the energy vortex in the Mithra's shrine). The energy field of a highly developed spiritual person supports the rise of an individual's level of awareness and allows entry into the state of spiritual connection of everything with everything (a condition described in my experience by the religious term bliss). The technically generated field doesn't have that ability. At the beginning of the vitality research, I prioritised the design (probably due to the study of architecture and feng shui), but today, based on the experience gathered, I estimate that the design is distinctly secondary and that the vitality of the physical space is crucially influenced by the people and processes using the physical space.

\section{CONCLUSION}

Fengshui's nature is distinctly dual, so we need to use both the tools of perception and apperception to understand it. It is because of its dual nature that Paton $(2007,438)$ describes it as one of the attempts to humanize science. In the West, the feeling is, that the magic and power of the individual has disappeared from life, because large scientific conglomerates control science through dry statistics. There is a need for modern humanistic scientific systems which would be able to integrate both the rational and emotional aspects. It is the mystical element in feng shui that is probably most credited to its popularity in the modern Western world. The main task of any religion is to offer basic answers to the questions of who we are, where we come from and where we are headed. In the alienation and spiritual emptiness of the post-industrial and postmodern society of the Western developed world, a great need for the creation of personal, social and spiritual meaning is created, which the Christian and Islamic historical metaphors can no longer satisfy. Therefore, new-age movements (including feng shui) appear as a substitute for all individuals who are left dissatisfied by modern scientific, positivist and rational world view (see e.g. MacDonald, 1995). In this context, modern feng shui is a historical metaphor that draws on historical tradition but transforms it to meet modern needs, by both East and West.

Feng shui is also a great example of cultural globalization. Of course, Westerners are not interested in feng shui as a culture associated with the worship of ancestors and the art of proper placement of graves or tombs. They regard it exclusively as the art of designing dwellings for the living (with an emphasis on the decorative aspect), as a technique of empowering the user and as a means of individualizing space. In this, the feeling of space (individual apperception) plays an important role.

Feng shui is also closely related to the concept of transgression due to its dual nature. Transgression usually refers to phenomena that transcend the boundaries of the ordinary, which represent a move away from social or moral conventions (Kos, 2012). And feng shui is, at present, beyond the transgressional boundaries of modern science, as it is generally classified as pseudoscience. We know from history that science in the early stages included various cognitive concepts: mathematics, metaphysics, hermeneutics and empirical testing. Since the Enlightenment era, science has evolved into a logical scientific system based on the methodical processing of empirical data and reproduction of the results obtained. Modern science is reluctant to transgressive thinking. Loosening the empirical point of view can lead to contact with the irrational, which is unacceptable to the prevailing scientific paradigm. Although creativity and innovation are embedded in the fundamental concept of science, they can only happen in the field of established system logic. In the context of transgression, feng shui can be seen as a system that encourages us to rethink the established perceptions of physical space and to transcend the established norms, principles and mechanisms of our action in this physical space. In this sense, feng shui can help us create new, more comprehensive spatial paradigms. 


\section{REFERENCES}

[1] Abraham, T., Wegars, P. (2003): »Urns, Bones and Burners: Overseas Chinese Cementeries«, Australasian Historical Archeology, 21, 58-69.

[2] Alexander, C. (2002a): The Phenomenon of Life - The Nature of Order, 1, Berkeley, Center for Environemntal Structure.

[3] Alexander, C. (2002b): The Process of Creating Life - The Nature of Order, 2, Berkeley, Center for Environemntal Structure.

[4] Alexander, C. (2004): The Luminous Ground - The Nature of Order, 4, Berkeley, Center for Environemntal Structure.

[5] Alexander, C. (2005): A Vision of a Living World - The Nature of Order, 3, Berkeley, Center for Environemntal Structure.

[6] Bateson, G. (2000): Steps to en Ecology of the Mind, Experiments in Thinking About Observed Ethnological Material, Chicago and London, The University of ChicagoPress.

[7] Blue, C. (2003): "Feng Shui Matrix, Artists' Statements", Leonardo, 37, 277 278.

[8] Boerschmann, E. (1912): »Chinese Architecture and its Relation to Chinese Culture«, Smithsonian Institute Report 1911, Washington, 539-577.

[9] Bowen, G. (2009): »Document Analysis as a Qualitative Research Method«, Qualitative Research Journal, 9, 2, 27-40.

[10] Braswell - Means, L. (1990): "The Popular Art of Geomancy in the Medieval west and Contemporary Asia", The Journal of Popular Culture, 23, 131.

[11] Bruun, O. (2003): Feng Shui in China, Geomantic Divination between State Orthodoxy and Popular Religion, Honolulu, University of Hawai Press.

[12] Bruun, O. (2008): An Introduction to Feng Shui, Cambridge, Cambridge University Press

[13] Chen, G. (2016): »Gods, Ghosts and Ancestors as Reflected in death Rituals in a Chinese Village«, Cultural Diversity in China, 2, 125-157.

[14] Creswell, J. W. (2009): Research Design: Qualitative, quantitative and Mixed Methods Approaches. Los Angeles, SAGE.

[15] Dawson, A. (2006): "East is East, except When It's West", Journal of Religion \& Society, $8,1-13$.

[16] De Groot, J. J. M. (1897): The Religious System of China., 1892 - 1910, 3 and 6, E. J. Brill, Leiden.

[17] Dong, W. (2017): »Integrating Feng Shui Concepts into Painting Creation«, Academic Journal of Feng Shui - 1st Symposium - Oceania, University of Technology Sydney, 13. - 14. of May 2017. Available at: http://ajofengshui.co.nf/wp content/uploads/2017/05/Dong_Wei_2017_Integrating_FS_Painting_Creati on L_P.pdf (10.3.2019)

[18] Eitel, E. J. (1873): Feng Shui - The Rudiments of Natural Science in China.

[19] Eitel, E. (transl. 2015): Feng shui, die Urspruenge der Naturwissenscaften in China, Froehling \& Froehling. Available at: https://www.deutschesfengshui-institut.de/wp-content/uploads/2015/11/Feng-Shui-Urspruenge.pdf $(1.10 .2016)$

[20] Emmons, C. F. (1992): »Hong Kong's Feng Shui: Popular Magic in a Modern Urban Setting «, Journal of Popular Culture, 26, 39-50.

[21] Feuchtwang, S. (1974): An Anthropological Analyses Of Chinese Geomancy, Bangkok, White Lotus.

[22] Fran, (2019): Slovarji Inštituta za slovenski jezik Frana Ramovša ZRC SAZU. Available at: https://fran.si/iskanje?View=1\&Query=percepcija (1.9.2019)

[23] Freedman, M. (1968): "Geomancy", Proceedings of the Royal Anthropological Institute of Great Britain and Ireland. Available at: https://www.jstor.org/stable/3031703?Search=yes\&resultItemClick=true\&s earchText=Geomancy\&searchText=M\&searchText=Freedman\&searchUri= \%2Faction\%2FdoBasicSearch\%3FQuery\%3DGeomancy\%2BM\%2BFreed man\%2B\&ab_segments $=0 \% 2 \mathrm{Ftbsub}-$

$1 \% 2$ Frelevance config with tbsub\&refreqid=search $\% 3 \mathrm{Ab} 181 \mathrm{ff} 0288 \mathrm{a} 988 \mathrm{f}$ bb2e785a18fb2a1a6\&seq=1\#page scan tab contents (6.6.2013)

[24] Goodall, H. L. (2001): Writing the American Ineffable or the Mystery and Practice of Feng Shui in Everyday Life, Qualitative Inquiry. Available at: https://journals.sagepub.com/doi/abs/10.1177/107780040100700101 (6.6.2013)

[25] Hamel, J. (1997): »Sociology, Common Sense, and Qualitative Methodology: The Position of Pierre Bourdieu and Alain Touraine«, The Canadian Journal of Sociology, 22, 1, 95-112.
[26] Heider, F. (1958): The Psychology of Interpersonal Relations, New York, John Wiley \& Sons

[27] Hsu, H. L. (2006): »Mimicry, Spatial Captation and Feng Shui in Han Ong's Fixer Chao«, MFS Modern Fiction Studies, 52, 675-704.

[28] Hwangbo, A. B. (1999): »A New Millennium and Feng Shui«, The Journal of Architecture, 4, 191-198.

[29] Hwangbo, A. B. (2002): "An Alternative Tradition in Architecture: Conceptions in Feng shui and Its Continuous Tradition«, Journal of Architecture and Planning Research, 19, 110-127.

[30] Juneja, P. (2020): »Desk Research - methodology and Techniques«. Available at: https://www.managementstudyguide.com/desk-research.htm (Accessed 15.9.2020)

[31] Kelley, H. H. (1992): „Common Sense Psychology and Scientific Psychology «, Annual Review of Psychology, 43, 1-23.

[32] Kos, D. (2012): »Transgresivnost v znanosti, literaturi in humanistiki«, Primerjalna književnost, 35, 2, 75-80.

[33] Kryžanowski, Š. (2012a): Feng shui - primerjalna študija izbranih tradicionalnih priporočil in sodobnih dognanj, Master's Thesis, Univerza v Ljubljani, Fakulteta za arhitekturo, Ljubljana.

[34] Kryžanowski, Š. (2012b): Feng shui, filozofija prostora in psihologija bivanja, Ljubljana, Mladinska knjiga.

[35] Kryžanowski, Š. (2019): Feng shui in apercepcija prostora - pregled znanstvenih prispevkov in terenska analiza učinkovitosti priporočil, $\mathrm{PhD}$ Thesis, Alma Mater Europaea - Institutum Studiorum Humanitatis, Fakulteta za podiplomski humanistični študij, Ljubljana.

[36] Kubny, M. (2008): Feng shui, die Struktur der Welt, Drachen Verlag.

[37] Lai, D. C. (1974): »A Feng Shui Model as a Location Index«, Annals of the Association of American Geographers, 64, 506 - 513.

[38] Lai, D. C. (1987): »The Chinese Cementary in Victoria«, BC Studies, 75, 24 42.

[39] Leung, K. (2010): »Beliefs in Chinese Culture« v The Oxford Handbook of Chinese Psychology, Bond, M. H. (ed.), Oxford Handbooks.

[40] Li, H. (2014): »Analyses of the Applicationof traditional Feng Shui Theory in Modern Home Space, Studies in Sociology, $5,3$.

[41] Lu, Z. (1997): Scientific Qigong Exploration: The Wonders and Mysteries of $Q i$, Malvern, Amber Leaf Press.

[42] Mak, M. Y., So, A. T. (eds.) (2009): Research in Scientific Feng Shui and the Built Environment, Hong Kong, City University of Hong Kong Press.

[43] March, A. L. (1968): »An Appreciation of Chinese Geomancy«, The Journal of Asian Studies, 27, 2, 253-267.

[44] Merriam (2018): Merriam-Webster. Available at: https://www.merriamwebster.com (6.5.2018)

[45] Mills, J. E. (1999): »Western Responses to Feng Shui«, Middle State Geographer, 32, 71-77.

[46] Montenegro, M. (2003): »Feng Shui: New Dimensions in Design«, Christian Research Journal, 26

[47] Needham, J. (1962): Science and Civilisation in China, Book 4: Physics and Physical Technology. Cambridge, Cambridge University Press.

[48] Osmanagich, S. (2014): Pyramids Around the World and Lost Pyramids of Bosnia, Sarajevo, Archeological Park Bosnian Pyramid of the Sun.

[49] Parkes, G. (2003): »Winds Waters and Earth Energies: Fengshui and Sense of Place«, v Selin, H. (ed), Nature Across Cultures, Science Across Cultures - The History of Non Western Science, Book 4. Dordrecht, Springer, 185209.

[50] Paton, M. (2007): »Fengshui: A Continuation of 'Art of Swindlers'?«, Journal of Chinese Philosophy, 34, 3, 427-445.

[51] Paton, M. (2013): Five Classics of Feng Shui, Chinese Spiritual Geography in Historical and Environmental Perspective, Leiden - Boston, Brill.

[52] Paavola, S. (2004): »Abduction as a Logic and Methodology of Discovery: the Importance of Strategies «, Foundations of Science, 9, 3, 267-283.

[53] Peirce, C. S. (1931 - 1958): »Collected Papers of Charles Sanders Peirce«, in Hartshome, C., Weiss, P. (ed. book 16) in Burks, A. W. (ed. book 7. - 8.). Cambridge, Harvard University Press.

[54] Peters, L. B. C. (1998): »Green Dragons and White Tigers on Gold Mountain: Feng Shui in Barkeville«, Historical News, 31, 17.

[55] Porter, L. C. (1920): «Feng Shui or How the Chinese Keep in Tune with Nature«, The Chinese recorder, American Presbyterian Mission Press. 
[56] Potter, J. M. (1970): »Wind, Water, Bones and Souls: The Religious World of the Cantonese Peasant«, Journal of Oriental Studies, 3, 139 - 153

[57] Sarton, G. (1927): Introduction to the History of Science, Baltimore, Williams and Wilkins, 345 .

[58] Smedslund, J. (1978): »Bandura's Theory of Self Efficacy: A Set of Common-Sense Theorems «, Scandinavian Journal of Psychology, 19, 1.

[59] Teather, E. K. (1999): "High Rise Home for the Ancestors: Cremation in Hong Kong", Geographical Review, 89, 409-430.

[60] Teather, E. K. (2001): "Time Out and Worlds Apart: Tradition and Modernity Meet in the Time Space of the Gravesweeping Festivals of Hong Kong", Singapore Journal of Tropical Geography, 22, 156-172.

[61] Teiser, S. F. (1995): "Popular Religion", Journal of Asian Studies, 54, 378395.

[62] Vittachi, N. (2009): Feng Shui Detective's Casebook, UK, Birlinn Publishers.

[63] Wan, W. W. N., Peiguan, W., Luk, C. L., Fam, K., Lou, J. J. X. (2012): »Priming Attitudes Toward Feng Shui«, Asian Journal of Business Research, 2, 55-68.

[64] Watson, J. L. (1976): »Anthropological Analyses of Chinese Religion«, The China Quarterly, 6, 355-364.

[65] Yan, X. (2018): »Dr. Yan Xin on Scientific Qigong Research«. Available at: http://www.yanxinqigong.net/research/index.htm (1.3.2018).
[66] Yang, C. K. (1961): Religion in Chinese Society, Berkley, University of California Press.

[67] Yang, K. C. (2003): »The Analysis of Funerary Land Planning and Siting: A Feng Shui Theory Perspective«. Available at: http://libwri.nhu.edu.tw:8081/Ejournal/4032000105.pdf (6.2.2018)

[68] Yuan, D. (2008): »Kanyu (Feng Shui): A Case of Re-interpretation of the Spirit of Space«, 16th ICOMOS General Assembly and International Symposium: Finding the Spirit of Place - between the Tangible and the Intangible, $29^{\text {th }}$ of September $-4^{\text {th }}$ of October 2008, Qubec, Canada.

\section{AUTHOR}

Špela KRYŽANOWSKI*, Assist. Prof. PhD, Arch.

Faculty of Design, Associated Member of the University of Primorska, Slovenia.

E-mail: spela.kry@gmail.com or spela.kryzanowski@fd.si 